\title{
Correction to: scBFA: modeling detection patterns to mitigate technical noise in large-scale single-cell genomics data
}

Ruoxin $\mathrm{Li}^{1,2}$ and Gerald Quon ${ }^{1,2,3^{*}}$

\section{Correction to: Genome Biol}

https://doi.org/10.1186/s13059-019-1806-0

Following publication of the original article [1], the following two errors were found in formulae:

1) In the method section titled "Benchmarking dimensionality reduction methods for scRNA-seq", the brackets should be removed from inside the square roots. The correct equation is shown below:

$$
\mathrm{MCC}=\frac{T P * T N-F P * F N}{(\sqrt{T P+F P}) *(\sqrt{T P+F N}) *(\sqrt{T N+F P}) *(\sqrt{T N+F N})}
$$

2) In the method section titled "Batch effect correction", the position of superscript in the subscript are incorrect. The correct equation is shown below.

$$
\boldsymbol{M}_{\operatorname{sub}\left(i^{\prime}, j\right)} \sim P\left(g^{-1}\left(\boldsymbol{x}_{\operatorname{sub}\left(i^{\prime}\right)}^{T} \boldsymbol{\beta}_{j}+\boldsymbol{z}_{\operatorname{sub}\left(i^{\prime}\right)}^{T} \boldsymbol{a}_{j}+u_{\operatorname{sub}\left(i^{\prime}\right)}+v_{j}\right)\right)
$$

\section{Author details}

${ }^{1}$ Graduate Group in Biostatistics, University of California, Davis, Davis, CA,

USA. ${ }^{2}$ Genome Center, University of California, Davis, Davis, CA, USA.

${ }^{3}$ Department of Molecular and Cellular Biology, University of California, Davis, Davis, CA, USA.

Published online: 21 November 2019

\section{Reference}

1. Li, Quon. scBFA: modeling detection patterns to mitigate technical noise in large-scale single-cell genomics data. Genome Biol. 2019;20:193 https://doi. org/10.1186/s13059-019-1806-0.

\footnotetext{
* Correspondence: gquon@ucdavis.edu

1 Graduate Group in Biostatistics, University of California, Davis, Davis, CA, USA

${ }^{2}$ Genome Center, University of California, Davis, Davis, CA, USA

Full list of author information is available at the end of the article
} 